\title{
Appropriate tongue blade width of the Dingman Mouth Gag for Japanese cleft palate patients with mandibular micrognathia
}

\author{
Koji Satoh*, TakakoAizawa, Yoshikazu Kobayashi and TarohOkui \\ Department of Dentistry and Oral - Maxillofacial Surgery, School of Medicine, Fujita Health University, 1-98, Dengakugakubo, Kutsukake, Toyoake, Aichi, 470- \\ 1192, Japan
}

\begin{abstract}
Objective: The purpose of this study is to determine the appropriate tongue blade width of Dingman Mouth Gag for Japanese cleft palate (CP) patients with mandibular micrognathia.

Methods: We investigated 22 isolated CP patients whose bilateral lower first deciduous molars (D) had erupted. Patients were divided into the micrognathia (MG) group (10 patients) and normognathia (NG) group (12 patients). Following items were investigated: gender, age (A) and weight (W) at the time of surgery, distance between the top of lingual cusps of bilateral lower Ds (D1), distance between the lingual deepest points of bilateral lower Ds (D2) and perpendicular distance from the midpoint of incisal margin of bilateral lower deciduous central incisors to the line connecting the most distal points of bilateral lower Ds (D3).

Results: There were significant differences in A and D3 between the groups. There were significant correlations between W and D3, D1and D3, D2 and D3 in the MG group. Excluding the attachment part to the mouth gag frame, we had assumption that the position $13.2 \mathrm{~mm}$ (equal to the median value of D3 in the MG group) posterior from the tip of the tongue blade would be corresponding to the D2 measurement point. The actual measured value for the small tongue blade width (D4) was $20.5 \mathrm{~mm}$, smaller than median value of $\mathrm{D} 2$ in the MG group.
\end{abstract}

Conclusions: We conclude the width of small tongue blade of Dingman Mouse Gag currently in use may be appropriate and no modification is required for the width.

\section{Introduction}

Perioperative airway management is often problematic in pediatric patients with cleft palate (CP) and mandibular micrognathia, as tracheal intubation can be occasionally difficult and there is an increased risk of postoperative tongue and laryngeal edema.

The Dingman Mouth Gag is applied during palatoplasty, we have encountered patients in whom this device could not be used because patients had trismus or the tip of the tongue blade impinged on the posterior pharyngeal wall.

In the previous study, we assessed the appropriate tongue blade length of the Dingman Mouth Gag for Japanese CP patients with mandibular micrognathia, it was suggested that a tongue blade of approximately $50 \mathrm{~mm}$ in length, shorter than the current minimum specifications might be appropriate [1].

The purpose of this study is to determine the appropriate tongue blade width for the modification of Dingman Mouth Gag for Japanese $\mathrm{CP}$ patients with mandibular micrognathia.

\section{Methods}

\section{Subjects}

Among patients who underwent palatoplasty at Fujita Health University Hospital (Aichi, Japan) from 2012 to 2013, we investigated 22 isolated CP patients whose bilateral lower first deciduous molars (D) had erupted.Patients were divided into two groups.
The micrognathia (MG) group consisted of 10 patients who attended a preoperative consultation with the Department of Anesthesiology because their medical history indicated that tracheal intubation or postoperative management would be problematic because of mandibular micrognathia. The normognathia (NG) group consisted of 12 patients who did not have any such history.

The MG group included six patients of non-syndromic Pierre Robin sequence (nsPRS), four patients of syndromic Pierre Robin sequence (sPRS). Three nsPRS patients and three sPRS patients were admitted to the intensive care unit for postoperative management while they were still intubated, each of these patients was extubated the following day.

\section{Methods}

The following six items were comparatively investigated in these groups.

\section{(1) Gender}

Correspondence to: Koji Satoh, Department of Dentistry and Oral - Maxillofacial Surgery, School of Medicine, Fujita Health University, 1-98, Dengakugakubo, Kutsukake, Toyoake, Aichi, 470-1192, Japan, Tel: +81-562-93-9258, Fax: +81562-93-9258, E-mail: kjsato@fujita-hu.ac.jp

Key words: mandibular micrognathia, cleft palate, mouth gag, width

Received: April 01, 2017; Accepted: April 11, 2017; Published: April 14, 2017 
(2) Age at the time of surgery

(3) Weight at the time of surgery

(4) Distance between the top of lingual cusps of bilateral lower Ds (D1)

(5) Distance between the lingual deepest points of bilateral lower Ds (D2)

(6) Perpendicular distance from the midpoint of incisal margin of bilateral lower deciduous central incisors to the line connecting the most distal points of bilateral lower Ds (D3)

Dental cast models were made for operative planning, D1, D2, and D3 were measured on each dental cast model three times by the same examiner using digital vernier caliper, then the mean values were calculated for analysis (Figure 1).

\section{Statistical analysis}

The statistical analyses were performed using a statistical analysis software program (JMP ${ }^{\circledR} 11$, SAS Institute Japan, Tokyo, Japan). Median values of D1, D2, and D3 of each group were evaluated using the Mann-Whitney U test. Spearman's rank correlation coefficient was used for correlational analyses between age/weight at the time of surgery and D1, D2, or D3, and between D1 and D3, D2 and D3. During these analyses, a probability (p)-value of $<0.05$ was considered to be statistically significant.

\section{Results}

The MG group included four male and six female patients, and the NG group included five male and seven female patients.

The median age at the time of surgery was 28 months in the MG group (interquartile range (IQR): 20.75 to 34.75 months) and 19.5 months in the NG group (IQR: 19 to 21 months). A significant difference was observed between the MG and NG groups ( $\mathrm{p}=0.0014$ ). The median weight at the time of surgery was $10.75 \mathrm{~kg}$ in the MG group (IQR: 9.68 to $12.95 \mathrm{~kg}$ ) and $9.95 \mathrm{~kg}$ in the NG group (IQR: 9.45 to $10.3 \mathrm{~kg}$ ), indicating no significant difference between the $\mathrm{MG}$ and NG groups $(\mathrm{p}=0.176)$.

The median D1 was $24.35 \mathrm{~mm}$ in the MG group (IQR: 23.73 to $25.63 \mathrm{~mm}$ ) and $24.2 \mathrm{~mm}$ in the NG group (IQR: 23.0 to $25.73 \mathrm{~mm}$ ), indicating no significant difference between the MG and NG groups $(\mathrm{p}=0.791)$ (Figure2).

The median D2 was $21.3 \mathrm{~mm}$ in the MG group (IQR: 20.78 to $23.33 \mathrm{~mm}$ ) and $22.5 \mathrm{~mm}$ in the NG group (IQR: 21.55 to $23.75 \mathrm{~mm}$ ), indicating no significant difference between the MG and NG groups $(\mathrm{p}=0.113)$ (Figure3).

The median D3 was $13.2 \mathrm{~mm}$ in the MG group (IQR: 12.65 to $14.3 \mathrm{~mm}$ ) and $16.5 \mathrm{~mm}$ in the NG group (IQR: 15.38 to $17.1 \mathrm{~mm}$ ), demonstrating a significant difference between the MG and NG groups $(\mathrm{p}=0.0001)$ (Figure4).

For the correlations between age/weight at the time of surgery and D1, D2, or D3, and between D1 and D3, D2 and D3, the correlation coefficients, Spearman's rank correlation coefficients, and p-values for all variables in each group were summarized in Table 1 .

In only the MG group, significant correlations were observed between weight at the time of surgery and D3 $(p=0.0204), D 1$ and D3 $(\mathrm{p}=0.0269)$, and D2 and D3 ( $\mathrm{p}=0.0178)$.

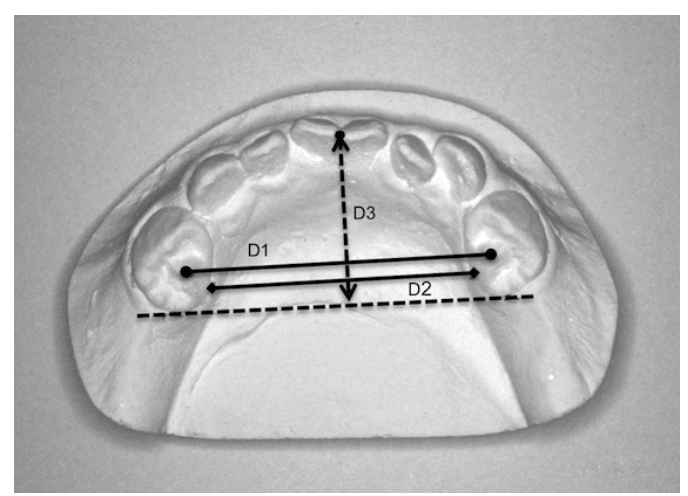

D1; Distance between the top of lingual cusps of bilateral lower Ds. D2; Distance between the lingual deepest points of bilateral lower Ds. D3; Perpendicular distance from the midpoint of incisal margin of bilateral lower deciduous central incisors to the line connecting the most distal points of bilateral lower Ds.

Figure1. Measurement items for lower dental cast model.

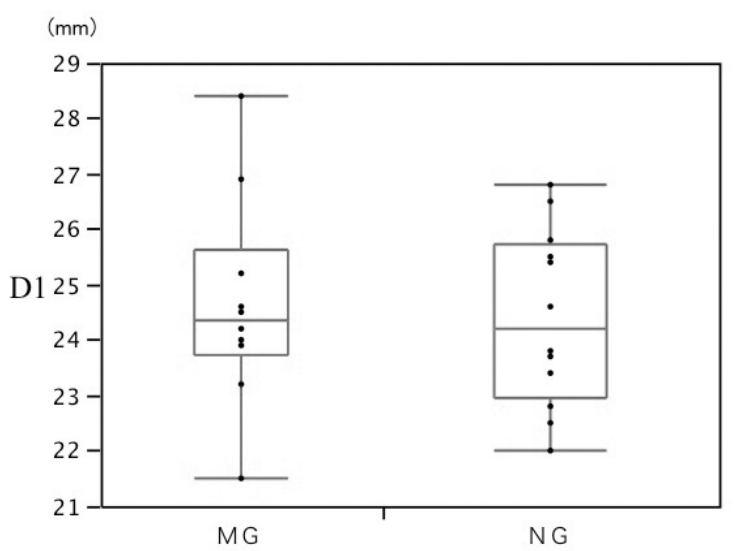

Figure 2. Distance between the top of lingual cusps of bilateral lower Ds (D1) of each group.

$(\mathrm{mm})$

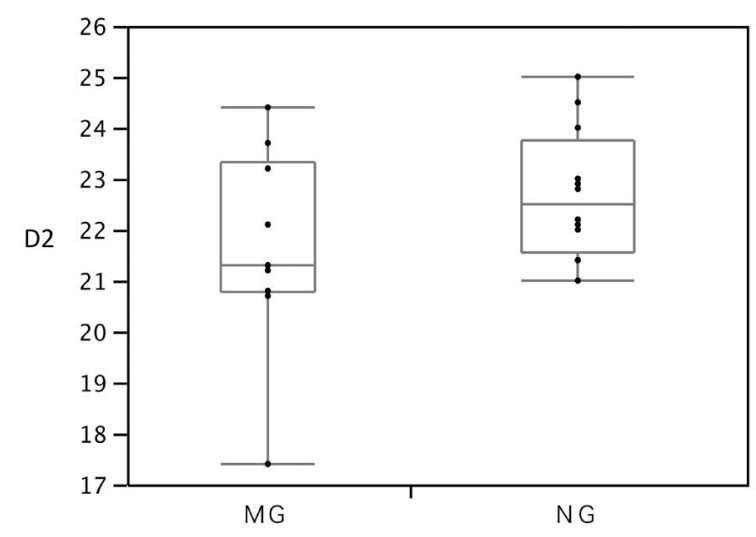

Figure 3. Distance between the lingual deepest points of bilateral lower Ds (D2) of each group.

\section{Discussion}

The history of improvements of mouth gags used for palatoplasty were first reported in the early 1900s, followed by a number of reports [2-5] up to the present. Even now, improved versions of the Dingman Mouth Gag are widely used in Japan. However, none of those reports 


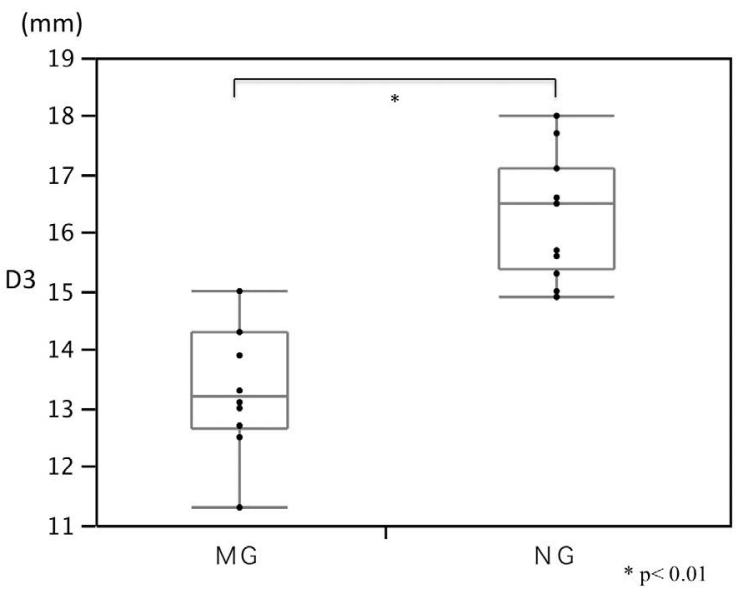

Figure 4. Perpendicular distance from the midpoint of incisal margin of bilateral lower deciduous central incisors to the line connecting the most distal points of bilateral lower Ds (D3) of each group.

Table 1. Correlations between measured variables.

\begin{tabular}{|c|c|c|c|}
\hline \multicolumn{4}{|c|}{ NG group } \\
\hline & $\begin{array}{c}\text { correlation } \\
\text { coefficient }\end{array}$ & $\begin{array}{c}\text { Spearman's } \\
\text { rank correlation } \\
\text { coefficient }\end{array}$ & p value \\
\hline age-D1 & 0.321 & 0.389 & 0.211 \\
\hline age-D2 & 0.037 & 0.103 & 0.750 \\
\hline age-D3 & 0.013 & 0.023 & 0.944 \\
\hline weight-D1 & 0.144 & 0.070 & 0.829 \\
\hline weight-D2 & 0.321 & 0.134 & 0.679 \\
\hline weight -D3 & -0.146 & -0.253 & 0.423 \\
\hline D1-D3 & -0.248 & -0.239 & 0.455 \\
\hline D2-D3 & -0.118 & -0.081 & 0.803 \\
\hline \multicolumn{4}{|c|}{ MG group } \\
\hline & $\begin{array}{c}\text { correlation } \\
\text { coefficient }\end{array}$ & $\begin{array}{c}\text { Spearman's } \\
\text { rank correlation } \\
\text { coefficient }\end{array}$ & p value \\
\hline age-D1 & 0.007 & 0.151 & 0.660 \\
\hline age-D2 & 0.028 & -0.193 & 0.569 \\
\hline age-D3 & 0.102 & 0.131 & 0.701 \\
\hline weight-D1 & 0.306 & 0.400 & 0.223 \\
\hline weight-D2 & 0.587 & 0.579 & 0.062 \\
\hline weight -D3 & 0.668 & 0.683 & $0.0204 *$ \\
\hline D1-D3 & 0.689 & 0.661 & $0.0269^{*}$ \\
\hline D2-D3 & 0.818 & 0.694 & $0.0178^{*}$ \\
\hline \multicolumn{4}{|c|}{ age; age at the time of surgery, weight; weight at the time of surgery } \\
\hline \multicolumn{4}{|c|}{$* \mathrm{p}<0.05$} \\
\hline
\end{tabular}

detailed information on its specifications for the length and width of the tongue blade.

The objective of applying a mouth gag during palatoplasty is to expose soft tissues including the tongue and buccal mucosa and to ensure the surgical field. The tongue blade, which is used to keep the mouth open and exclude the tongue, needs to fit the tongue without causing excessive postoperative swelling, and also to fixate the endotracheal tube without causing obstruction.

We were told that a modification to the device could be made upon request from the Japanese manufacturer of the mouth gag used in our institute.

So in the previous study, we attempted to determine appropriate tongue blade length for Japanese pediatric patients with $\mathrm{CP}$ and mandibular micrognathia and concluded that it was difficult to predict the distance from the tongue blade base to the posterior pharyngeal wall (Dis) on the basis of the patient's age or weight at the time of surgery, which could be measured preoperatively, and as the minimum Dis value in the MG group was $55 \mathrm{~mm}$, preparing a tongue blade of approximately $50 \mathrm{~mm}$ in length, which is shorter than the current minimum specifications, might be appropriate when fitting a Dingman Mouth Gag for Japanese pediatric patients with CP and mandibular micrognathia [1].

It is difficult to measure the form of tongue because it is mobile soft tissue. For the width of the tongue blade, it is defined by immobile hard tissue, such as lower dental arch consisted of teeth and alveolar bone, so in this time, we conducted our study using measure points set on lower dental cast model.

We investigated 22 isolated CP patients whose bilateral lower Ds had erupted. The results indicated that no significant differences were observed between the MG and NG groups in D1 and D2, which were items related to the width of dental arch. Meanwhile, D3, which represented the antero- posterior length of dental arch, was significantly shorter in the MG group than in the NG group.

Our results also indicated that significant correlations existed between weight at the time of surgery and D3, D1 and D3, and D2 and D3 in the MG group. Only in the MG group, significant correlations were observed between anteroposterior length and width of dental arch.

Excluding the attachment part to the mouth gag frame, we had assumption that the position $13.2 \mathrm{~mm}$ (equal to the median value of D3 in the MG group) posterior from the tip of the tongue blade would be corresponding to the $\mathrm{D} 2$ measurement point. The actual measured value for the width of the small tongue blade currently in use (D4) was $20.5 \mathrm{~mm}$ (Figure 5). D4 was smaller than median value of D2 in the MG group.

There are several limitations to the present study: 1) the number of patients is rather small; the birth prevalence of $\mathrm{CL} / \mathrm{P}$ and $\mathrm{CP}$ is approximately 1:500 in Japan[6]. PRS occurs in approximately 1 per

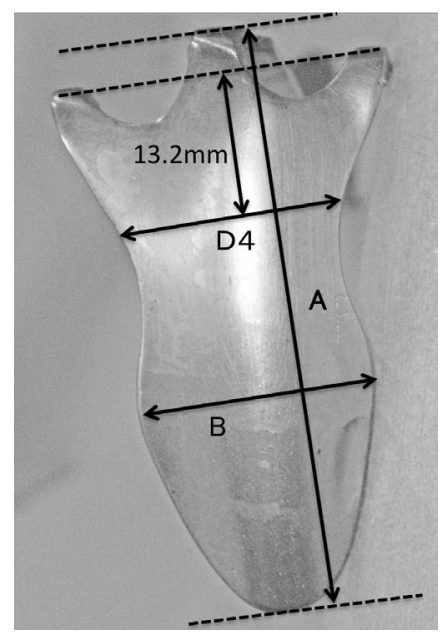

A; From base to tip: $55 \mathrm{~mm}$

B; Maximum width: $25 \mathrm{~mm}$

D4; Width at the position of $13.2 \mathrm{~mm}$ (equal to the median value of D3 in the MG group) posterior from the tip of the tongue blade excluding the attachment part to the mouth gag frame: $20.5 \mathrm{~mm}$.

Figure 5. Small tongue blade of the Dingman Mouth Gag currently in use at our hospital. 
8500 to 1 per 14000 births[7,8]. Considering a situation like this, we think it is difficult to increase the size of the MG cohort in only one single institution because the percentage of patients with mandibular microgenia among all cleft palate patients is not so high. 2) The patients are all Japanese; as subjects are patients who underwent palatoplasty at our hospital, our conclusions are only for Japanese pediatric patients with $\mathrm{CP}$ and mandibular micrognathia. We expect further studies on other human groups for comparison.

\section{Conclusions}

When fitting a Dingman Mouth Gag for Japanese pediatric patients with $\mathrm{CP}$ and mandibular micrognathia, it was suggested that a tongue blade of approximately $50 \mathrm{~mm}$ in length, which was shorter than the current minimum specifications, might be appropriate in the previous study [1].

In the present study we conclude that the width of small tongue blade of Dingman Mouse Gag currently in use at our hospital may be appropriate and no modification is required for the width of tongue blade.

\section{Ethical approval}

This study was conducted with clinical practices, following the approval of Institutional Review Board of Fujita Health University (15-249).

\section{Conflict of interest}

The authors declare no conflicts of interest related to this article.

\section{References}

1. Satoh K, Aizawa T, Kobayashi Y, Mizutani H, Yamada M (2016) Appropriate Tongue Blade Length of the Dingman Mouth Gag for Japanese Pediatric Patients With Cleft Palate and Mandibular Micrognathia. Cleft Palate Craniofac J 53:157-160. [Crossref]

2. Dingman RO, Grabb WC (1962) A new mouth gag. Plast Reconstr Surg Transplant Bull 29:208-209. [Crossref]

3. Bodley P (1978) Development of anaesthesia for plastic surgery. J R Soc Med 71:839843. [Crossref]

4. Bloem JJ, Hage JJ (1993) The cleft palate gag line: connect the Dotts. Ann Plast Surg 30:475-478. [Crossref]

5. Sommerlad BC, Mehendale FV (2000) A modified gag for cleft palate repair. $\mathrm{Br} J$ Plast Surg 53:63-64.

6. World Health Organization. Global strategies to reduce the health-care burden of craniofacial anomalies. Available:www.who.int/iris/handle/10655/42594 [Accessed 8 November 2014].

7. Bush PG, Williams AJ (1983) Incidence of Robin Anomalad (Pierre Robin syndrome). Br J Plast Surg 36:434-437. [Crossref]

8. Printzlau A, Andersen M (2004) Pierre Robin sequence in Denmark: a retrospective population- based epidemiological study. Cleft Palate Craniofac J 41:47-52. [Crossref]

Copyright: (C2017 Satoh K. This is an open-access article distributed under the terms of the Creative Commons Attribution License, which permits unrestricted use, distribution, and reproduction in any medium, provided the original author and source are credited. 